UDC 321

Submitted: 28.04.2016

LBC 66.2(2Poc)

Accepted: 25.05 .2016

\title{
SOCIAL CONTRACT-2030 - A MODERN INSTITUTION IN IMPLEMENTING THE INTERACTION BETWEEN THE STATE, SOCIETY AND BUSINESS
}

\author{
Aleksandr V. Ponedelkov \\ South-Russian Institute of Management - Branch of Russian Presidential Academy \\ of National Economy and Public Administration, Rostov-on-Don, Russian Federation \\ Svetlana I. Kuzina \\ South-Russian Institute of Management - Branch of Russian Presidential Academy \\ of National Economy and Public Administration, Rostov-on-Don, Russian Federation

\section{Tatyana P. Cherkasova} \\ South-Russian Institute of Management - Branch of Russian Presidential Academy \\ of National Economy and Public Administration, Rostov-on-Don, Russian Federation
}

\begin{abstract}
The article is devoted to analysis of formation processes of interaction between the state, civil society and business in Russia. As an empirical basis the authors use the results of sociological research conducted by Public Opinion Fund in 2015, scientists of the South-Russian Institute of Management - Branch of Russian Presidential Academy of National Economy and Public Administration in 2012 and 2016. $44 \%$ of respondents in the regions expressed a preference for the social partnership of government, business and civil society. The authors believe that the implementation of the mission of the Social Contract-2030 is possible through the mechanism of public-private partnership (PPP), which is the most promising and effective institution in modern economicpolitical condition of Russia. The strategic goals of the state consist in providing transfer of the country to the path of innovative development, aimed at reducing the export-resource dependence of the country in the context of the mission of Social Contract-2030 and the national security strategy of the country is impossible without formation of a partnership between the state, companies and commercial structures. Each of the members of the partnership provides a contribution to the implementation of the project. The business structure for its part contributes investment funds, human resources, effective business technologies, flexibility and responsiveness in decision-making, innovation and other private initiatives and available resources. The state in turn provides a partnership through their powers with necessary legal and institutional resources that ensure protective measures for the formation of a competitive and low-risk business. The main task of civil society is to help citizens in solving if social problems and the implementation of control over the power structures in the fulfillment of social obligations of the state. The question of increasing the efficiency of mechanisms of Social contract-2030 implementation between the state, society, and business implies transparency of activities of public authorities and effective management of results.

Key words: Social Contract-2030, civil society, public-private partnership, power, business.

\section{«ОБЩЕСТВЕННЫЙ ДОГОВОР-2030»-СОВРЕМЕННЫЙ ИНСТИТУТ} РЕАЛИЗАЦИИ ВЗАИМОДЕЙСТВИЯ ГОСУДАРСТВА, ОБЩЕСТВА И БИЗНЕСА
\end{abstract}

\author{
Александр Васильевич Понеделков \\ Южно-Российский институт управления - филиал РАНХиГС при Президенте РФ, \\ г. Ростов-на Дону, Российская Федерация
}


А.В. Понеделков, С.И. Кузина, Т.П. Черкасова. «Общественный договор-2030»- современный институт

\section{Светлана Ивановна Кузина}

Южно-Российский институт управления - филиал РАНХиГС при Президенте РФ, г. Ростов-на Дону, Российская Федерация

\section{Татьяна Павловна Черкасова}

Южно-Российский институт управления - филиал РАНХиГС при Президенте РФ, г. Ростов-на Дону, Российская Федерация

Аннотация. Статья посвящена анализу процессов формирования взаимодействия государства, гражданского общества и бизнеса в России. В качестве эмпирической базы по исследуемым вопросам были использованы результаты социологических исследований, проводившихся Фондом общественного мнения в 2015 г., учеными Южно-Российского института управления - филиала РАНХиГС при Президенте РФ в 2012 и 2016 годах. По поводу механизмов взаимоотношения власти, бизнеса и гражданского общества 44 \% опрошенных в регионах отдали предпочтение их социальному партнерству. Авторы полагают, что реализация миссии «Общественного договора-2030» возможна через механизм государственно-частного партнерства (ГЧП), который является наиболее перспективным и эффективным институтом в современных экономикополитических условиях России. Достижение стратегических целей государства по обеспечению перевода страны на инновационный путь развития, ориентированный на снижение экспортно-ресурсной зависимости страны в контексте миссии «Общественный договор-2030» и стратегии национальной безопасности страны, невозможно без формирования партнерских отношений государства, общества и коммерческих структур.

Ключевые слова: «Общественный договор-2030», гражданское общество, государственно-частное партнерство, власть, бизнес.

Гражданская политическая активность является составной характеристикой гражданского общества как одного из институтов политической системы. Но в отрыве от вопросов власти ни один из политических институтов рассмотреть невозможно, так как «...к политической системе относятся институты, непосредственно связанные с изменением и осуществлением власти в государстве» [1, с. 32].

Наличие гражданского общества в стране означает определенную степень свободы граждан в политических и экономических отношениях с государством. Граждане имеют возможность развития в личностном плане, а также в публичной сфере, где формируются и развиваются их коллективистские качества, необходимые для участия граждан в политических партиях, общественных движениях и прочих институтах демократического общества. Государство же не только создает условия для проявления гражданских инициатив, поддерживает демократические институты, но и требует от граждан понимания и проявления своей ответственности за общественные действия. Чем большее количество граждан проявляет политическую и просто гражданскую активность в рамках современной правовой и политической культуры, тем масштабней гражданское общество в государ- стве, тем выше его роль модулятора общественных процессов. Такая парадигма может быть отражена в проектируемом «Общественном договоре-2030».

Дискуссия о формировании гражданского общества в России ведется с реформенного периода 90-х гг. ХХ в., в том числе и в контексте строительства более разветвленной политической системы, ее связи с государством и обществом. В настоящее время можно констатировать следующую динамику политической системы: укрепление вертикали власти с приходом нового лидера государства в начале 2000-х гг. привело к некоторому упрощению политической системы. Имидж молодого, энергичного, открытого для дискуссии с обществом, популярного политического лидера в общественном сознании начал ассоциироваться с имиджем государственной власти и политической элиты. Российской власти в те годы удалось убедить население в том, что она способна самостоятельно, без помощи гражданского общества выстроить эффективную политическую систему.

В 2015 г. была принята новая «Стратегия национальной безопасности Российской Федерации» [6]. И если до недавнего времени гражданское общество находилось несколько вне приоритетных направлений государ- 
ственной политики, то в новой Стратегии четко прописано, что одним из главных направлений обеспечения государственной и общественной безопасности является развитие взаимодействия органов ее обеспечения с гражданским обществом. Взаимодействие органов государственной и муниципальной власти с гражданским обществом должно быть направлено на противодействие угрозам качеству жизни россиян.

Главную задачу гражданского общества государство видит в помощи граждан в решении социальных проблем и осуществлении контроля за работой властных структур в выполнении социальных обязательств государства. Таким образом, власть определяет место гражданского общества в политической системе в настоящий момент.

Всероссийский центр изучения общественного мнения россиян - Фонд общественного мнения (ФОМ) в сентябре 2015 г. провел опрос населения на тему «Что такое “гражданское общество?"» [8].

Из опрошенных на вопрос «Знаете ли Вы, слышали или слышите сейчас впервые выражение “гражданское общество”?» 52 \% ответили, что знают или что-то слышали, 33 \% ответили, что впервые слышат об этом, а $15 \%$ затруднились с ответом.

Следующий вопрос задавался тем $52 \%$ респондентов, кто знает, что такое гражданское общество. Вопрос звучал так: «По Вашему мнению, в России сейчас есть гражданское общество или гражданского общества нет?». Ответы распределились в следующем соотношении: $31 \%$ ответили, что есть; $13 \%$ нет; $8 \%$ затруднились ответить. Тех же граждан попросили ответить на вопрос, как они понимают выражение «гражданское общество», что оно означает. Ответы распределились таким образом (см. таблицу). Необходимо отметить, что вопрос был открытым, граждане развернуто поясняли свои ответы.

Анализ развернутых ответов тех, кто знает, что такое гражданское общество, позволяет утверждать, что россияне в большинстве своем имеют представление, что такое гражданское общество в соответствии с его классическими определениями, в том числе в части необходимости правового, свободного, демократического государства.
Политическая ситуация в стране определяется во многом состоянием общественных отношений в ее регионах. В 2012 г. ЮжноРоссийским институтом - филиалом Российской академии народного хозяйства и государственной службы при Президенте Российской Федерации в рамках подготовки к Круглому столу «Проблемы взаимодействия гражданского общества, государства и бизнеса: опыт России и Германии» был проведен социологический опрос среди экспертов в сферах государственной гражданской службы, бизнеса, научного сообщества, общественных и политических организаций [2]. Было опрошено 2500 человек из семи субъектов Российской Федерации. На вопрос: «Как Вы оцениваете взаимодействие гражданского общества, государства и бизнеса в современной России?» в среднем $53 \%$ от общего числа опрошенных ответили «отрицательно» и «скорее отрицательно». Данный сдвиг в сторону отрицательных оценок во многом можно объяснить последствиями кризиса российской экономики, спадом в реальном и финансовом секторах в 2009-2010 гг. и затяжной стагнацией в 20112016 годах. Однако не менее значимым, чем воздействие текущей экономической ситуации, представляется сохраняющаяся институциональная неопределенность предпринимательской среды и организационная слабость институтов гражданского общества. Оценки в разных регионах варьируются от $32 \%$ в Республике Калмыкия до 76 \% в Калининградской области, что также можно объяснить уровнем осведомленности граждан о понятии «гражданское общество».

Следующим вопросом был «На чем, по Вашему мнению, должны быть основаны отношения между представителями гражданского общества, государством и бизнесом?». Из предложенных ответов на первом месте «На принципах социального партнерства» $(44,07 \%)$; на втором - «Главенствующая роль в данных отношениях должна принадлежать государству» $(22,65 \%)$; на третьем - «Вектор взаимодействия должны устанавливать представители гражданского общества» $(15,46 \%)$. Хотя есть и отличающиеся ответы. Так, в Калининградской области эксперты отдали предпочтение ответу «Наличие финансовых ресурсов у бизнеса позволяет его 
Ответы на вопрос

«Как Вы понимаете выражение "гражданское общество", что оно означает?»"

\begin{tabular}{|c|c|}
\hline Ответы респондентов & $\begin{array}{c}\text { \% от доли } \\
\text { группы }\end{array}$ \\
\hline $\begin{array}{l}\text { Население страны, граждане, общество, все мы } \\
\text { «Все люди, народ»; «жители городов и сел страны»; «каждый член общества - гражданин»; } \\
\text { «люди, живущие вокруг нас»; «наш народ весь - это и есть гражданское общество»; «это все } \\
\text { мы, граждане России» }\end{array}$ & 10 \\
\hline $\begin{array}{l}\text { Общество людей с высокой гражданской активностью, ответственностью } \\
\text { «Активные граждане, занимающие активную позицию в нашей стране»; «активные граждане, } \\
\text { которые не молчат, борются»; «более сознательные граждане страны»; «социально активные } \\
\text { граждане» }\end{array}$ & 7 \\
\hline $\begin{array}{l}\text { Группы граждан, объединенных общими идеями, целями, интересами } \\
\text { «Граждане, объединенные одними целями и задачами»; «союз граждан - единые цели, единый } \\
\text { смысл»; «группа людей, объединенная целью, задачей, - партия, например»; «общественные } \\
\text { организации»; «общество, которое чем-либо объединяет граждан» }\end{array}$ & 6 \\
\hline $\begin{array}{l}\text { Правовое, свободное, демократическое общество } \\
\text { «Граждане всей страны, подчиняющиеся законам»; «защищающее права граждан»; «это когда } \\
\text { гражданин может реализовать свои права»; «общество независимых людей»; «свободное, де- } \\
\text { мократическое общество, учитываются все слои населения и их проблемы»; «демократия, хоть } \\
\text { и мнимая, в нашей стране» }\end{array}$ & 6 \\
\hline $\begin{array}{l}\text { Общество граждан, способных влиять на власть, решать социальные вопросы } \\
\text { «Как граждане страны влияют на внутреннюю политику государства»; «контроль народа над } \\
\text { властью»; «общество, которое принимает непосредственное участие в политике»; «решение } \\
\text { вопросов общегражданских»; «ответственное самоуправление граждан» }\end{array}$ & 4 \\
\hline $\begin{array}{l}\text { Общество граждан, проявляющих единство и сплоченность } \\
\text { «Все граждане - одно целое»; «граждане, единые для каких-то действий»; «граждане сплочен- } \\
\text { ные»; «когда все вместе»; «это когда все заодно» }\end{array}$ & 3 \\
\hline $\begin{array}{l}\text { Развитое, цивилизованное, культурное общество } \\
\text { «Общество с культурными людьми»; «развитое общество»; «щивилизованное государство» }\end{array}$ & 1 \\
\hline $\begin{array}{l}\text { Общество людей, наделенных патриотизмом } \\
\text { «Гордость за Родину»; «люди с чувство м патриотизма, с верой в свою страну»; «общество } \\
\text { патриотов» }\end{array}$ & 1 \\
\hline $\begin{array}{l}\text { Конкретные категории граждан } \\
\text { «Рабочие, бюджетники. Богатые - не гражданское общество»; «средний класс»; «граждане без } \\
\text { военных»; «не политики, все остальные» }\end{array}$ & 1 \\
\hline $\begin{array}{l}\text { Общество людей, проявляющих заботу о других людях } \\
\text { «Когда граждане помогают и заботятся друг о друге»; «люди, которые помогают народу»; } \\
\text { «каждый гражданин обязан не только о себе думать, но и о других. Заботиться о стариках, ко- } \\
\text { торые войну прошли, и вообще о пожилых»; «любовь к ближнему» }\end{array}$ & 1 \\
\hline $\begin{array}{l}\text { Другое } \\
\text { «Добропорядочные люди»; «общество, где хорошо гражданам»; «это общество счастливых } \\
\text { людей»; «к церкви, например, относится»; «когда все равны перед Богом»; «система взаимо- } \\
\text { отношений между людьми, проживающими в одном государстве» }\end{array}$ & 2 \\
\hline Затрудняюсь ответить, нет ответа & 12 \\
\hline
\end{tabular}

* Вопрос задавался тем, кому знакомо понятие «гражданское общество», отвечали 52 \% респондентов.

представителям устанавливать свои правила в данных взаимоотношениях» $(36,54 \%)$, а в Ставропольском крае предпочитают ведущую роль государства (44\%).

В поисках предложений общественности о возможных путях развития взаимодействия государства, гражданского общества и бизнеса был задан вопрос: «Каков, с Вашей точки зрения, путь повышения эффективности механизма взаимодействия общества, го- сударства и бизнеса?». Самым популярным стал ответ «Повышение прозрачности текущей деятельности органов власти»- средний процент $(33,58)$; далее - «Обеспечение оперативности и полноты решений по проблемным вопросам» $(23,81 \%)$ и «Общественная экспертиза проектов принимаемых решений» $(23,05 \%)$.

Учеными ЮРИУ РАНХиГС в рамках подготовки к Круглому столу «Власть, биз- 
нес, гражданское общество: модели взаимодействия (российский и европейский опыт)» в 2016 г. проводился социологический опрос, вопросы которого повторяли вопросы опроса 2012 года. Для сравнения: в Челябинской области число экспертов, которые считают, что взаимодействие государства, бизнеса и общества должно основываться на социальном партнерстве, увеличилось с 58,7 до 63,8 \%; большее количество опрошенных стали придавать значение роли государства в данном процессе (с 17,3 до 23,5 \%), а вот роль гражданского общества снизилась с 11 до 5,9\%. Предварительно объяснить эти изменения можно решением властей формализовать гражданское общество через организацию Общероссийского национального фронта (ОНФ), созданного по инициативе Президента РФ. По поводу механизмов взаимоотношения власти, бизнеса и гражданского общества эксперты числом голосов в $44 \%$ отдали предпочтение их социальному партнерству.

В контексте полученных результатов, на наш взгляд, реализация миссии «Общественного договора-2030» возможна через механизм государственно-частного партнерства (ГЧП), который является наиболее перспективным и эффективным институтом в современных экономико-политических условиях России.

Государственно-частное партнерство это институциональный и организационный альянс между государством и бизнесом в целях реализации общественно значимых проектов и программ в широком спектре инновационных и ряде промышленных отраслей. ГЧП способствует нейтрализации одновременно «провалов» прямого государственного регулирования за счет учета общественной инициативы и «фиаско рынка», проявляющихся в том числе в форме финансово-экономических, структурных и системных кризисов. Основным аргументом в поддержку ГЧП является то, что государственный (общественный, публичный) и частный секторы имеют собственные уникальные характеристики и преимущества, объединение которых дает не просто возможность эффективно функционировать и добиваться наилучших результатов в секторах, для которых особо характерны «фиаско рынка» или низкая эффективность государственного регулирования, но и полу- чать синергетический институциональный эффект. Он проявляется в виде многократно усиливающихся конкурентных преимуществ новой институциональной структуры (ГЧП) за счет минимизации коммерческого риска, с одной стороны, и бюрократического статизма - с другой. Мировой опыт развитых стран демонстрирует эффективность института ГЧП в таких сферах, как социальная, экологическая, инфраструктурная.

Синергетический эффект ГЧП проявляется в росте инвестиционной привлекательности проектов, поскольку подобные партнерства имеют особую финансовую устойчивость, гарантированную участием государства, которое обеспечивает решение общественно значимых проблем в социально-инфраструктурной сфере за счет ресурсов бизнеса. В итоге реализуемые ГЧП-проекты обеспечивают устойчивый рост национальной экономики при одновременном решении социальных вопросов.

Базовыми характеристиками ГЧП-проектов являются следующие:

- участниками проекта выступают государственные органы власти и коммерческие структуры (бизнес), обеспечивая публичный характер партнерства;

- взаимодействие участников ГЧП осуществляется на официально-правовой основе, то есть оформляется в форме соглашений, договоров, контрактов и др.;

- взаимодействие участников реализуется на принципе равноправия сторон, что предполагает обеспечение баланса общественногосударственных выгод и частно-коммерческих выгод бизнеса от реализации партнерства;

- цель проекта - достижение публичного, общественного, национального интереса;

- в ходе реализации ГЧП-проектов происходит консолидация активов (ресурсов и вкладов) участников;

- ресурсно-финансовые затраты и риски, как и результаты, полученные от реализации ГЧП-проектов, распределяются между участниками в соответствии с пропорциями, зафиксированными в заключенных партнерских договорах, соглашениях, контрактах и др.; нормативно-правовых документах [4, с. 104].

Современные кризисы демонстрируют, что основным условием успешного функционирования национальной системы с точки зре- 
ния ее финансовой, экономической, социальной и политической стабильности выступает конструктивное сотрудничество государства с бизнес-структурами, в процессе которого формируются потребности в новых бизнесидеях, управленческих инновациях, частных инвестициях и предпринимательском таланте для создания объектов и эффективного управления ими, хотя приватизация этих объектов невозможна с позиций общественных интересов и национальной безопасности.

Достижение стратегических целей государства по обеспечению перевода страны на инновационный путь развития, ориентированный на снижение экспортно-ресурсной зависимости страны в контексте миссии «Общественный договор-2030» и стратегии национальной безопасности страны невозможно без формирования партнерских отношений государства с коммерческими структурами. Программы развития, ориентированные на финансирование за счет только бюджетных источников, часто не дают государственным органам возможности реализовывать крупномасштабные макропроекты стратегического значения, определяющие конкурентоспособность страны в мировых рейтингах. Оптимальным механизмом реализации таких макропроектов выступает государственночастное партнерство.

Каждый из участников партнерства обеспечивает свой вклад в реализацию проекта. Бизнес-структуры со своей стороны в качестве вклада вносят: инвестиционные средства, кадровые ресурсы, эффективные бизнестехнологии, гибкость и оперативность в принятии решений, инновационные разработки и другие частные инициативы и имеющиеся в их распоряжении ресурсы. Бизнес-партнер в реализацию совместного проекта, как правило, привносит эффективные методы работы, современную технику и технологию, новые организационно-производственные механизмы создания и ведения бизнеса, в том числе с участием иностранного капитала, налаженные кооперационные связи с подрядчиками и поставщиками.

Государство, в свою очередь, создает условия для партнерства через свои властные полномочия необходимыми институционально-правовыми ресурсами, обеспечивающими протекционистские меры для формирования конкурентоспособного и низкорискованного бизнеса. Немалую роль в этом играет и бюджетно-финансовый потенциал государства, дополняющий частные инвестиции бизнеса. С точки зрения выделенных преимуществ механизм ГЧП может быть использован при разработке и реализации стратегически значимых инновационных проектов [5].

Становление и развитие ГЧП в России имеет свою специфику, позволяющую выделить три хронологических этапа, обусловленных особенностями политической силы самого государства и эффективности бизнеса на каждом из них.

1. Этап создания организачионно-правовой базы для реализации ГЧП-проектов в условиях формирования рыночной экономики (1991-1998 г2.). Данный этап можно рассматривать как стартовую площадку, в этот период зарождается частное предпринимательство, происходит процесс формирования рыночной экономики в России. Главенствующую роль в создании рамочных условий организации первых форм партнерства государства и бизнес-структур сыграли такие объективные факторы национального развития, как институциональный упадок и глубочайший системный кризис.

Доминантами взаимодействия коммерческих структур с органами власти стали: концентрация собственности и частных инвестиций главным образом в сырьевой сфере; ориентация предпринимательского сектора на возможность получения быстрого дохода, на получение краткосрочной прибыли без учета стратегических целей долгосрочного развития; широкое использование административных ресурсов для удовлетворения экспансионистского интереса.

Приватизация и перераспределение собственности обеспечили возможность сформировать слой предпринимательских структур, сыгравших решающее значение в формировании ГЧП. Партнерство государства и бизнеса на этом этапе характеризовалось частно-олигархической моделью взаимодействия участников с доминирующим воздействием крупных акционерных компаний. Это, в свою очередь, спровоцировало появление серьезных барьеров, препятствующих формированию 
эффективных форм ГЧП, дестимулирующих коммерческие структуры к длинным инвестициям и технологическому обновлению: коррупция, рейдерство, взаимопроникновение олигархического бизнеса и власти. Основной формой ГЧП стали финансово-промышленные группы (ФПГ).

2. Этап экстенсивного развития ГЧП, сопровождавшийся экономическим ростом в стране (1999-2008 г2.). Этот период считается наиболее благоприятным этапом развития российской экономики, он характеризуется посткризисным восстановлением, макроэкономической и политической стабилизацией.

Устойчивые (почти $6 \%$ ) темпы ежегодного экономического роста обеспечили возможность наращивания бюджетного финансирования социальных и инфраструктурных проектов, системного развития особых экономических зон, создания институционально-правовой базы концессии, развития отношений аренды и лизинга. Однако усилившаяся зависимость экономики страны от ресурсно-сырьевого экспорта спровоцировала ориентацию частно-инвестиционных потоков в экспортносырьевой сектор и его инфраструктуру, что предопределило и отраслевую принадлежность реализуемых ГЧП-проектов.

Отличительной чертой второго этапа стало усиление регулирующего воздействия государства на экономику страны. Были задействованы такие инструменты государственной политики, как институты развития, предполагающие масштабное внедрение механизма ГЧП при реализации стратегических направлений развития национальной экономики: модернизация, диверсификация и реиндустриализация. Основным партнером государства и главным субъектом частно-инвестиционной инициативы в совместных проектах выступил крупный бизнес. К сожалению, роль малого бизнеса в реализации ГЧП-проектов осталась незначительной. Отсутствие положительной динамики в становлении институциональной среды ГЧП: кризис в сфере правоприменения, монополизм, коррупция - тормозят его развитие. Централизация бюджетных и частных ресурсов, углубление региональной социально-экономической асимметрии привели к концентрации ГЧП преимуще- ственно в Центральном федеральном уровне и городах федерального значения.

3. Этап дифференциации ГЧП в контексте антикризисной политики государства (2008-2015 г2.) обусловлен последствиями мирового финансово-экономического кризиса, обострившего проблемы ресурсоориентированного экспортного развития и зависимости национальной экономики от конъюнктуры мирового рынка сырья. В итоге после двухлетнего кризиса российская экономика стагнирует, социальная напряженность растет.

Возросшая потребность в диверсификации отечественной экономики и обеспечении ее перевода на инновационный путь развития актуализировала использование ГЧП-проектов в инновационной сфере.

Сегодня сформированы широкие возможности использования различных форм ГЧП в России. Особой динамикой отличаются такие сферы применения ГЧП, как государственные закупки и контракты в строительстве платных автомагистралей, развитии городского пассажирского транспорта, управлении жилищным фондом и т. д. Распространение арендно-лизинговых форм ГЧП обеспечивается государственными смешанными компаниями и корпорациями (ОАО «Росагролизинг»), внедрение новых моделей ГЧП реализуется посредствам институтов экономического развития (ОАО «Российская венчурная компания»; Инвестиционный фонд РФ; Внешэкономбанк; госкорпорации «Ростехнологии», «Росатом»; OAO «Особые экономические зоны» и др.). Концессия как форма ГЧП не нашла достаточного распространения в отечественной практике.

Распространение института ГЧП, повышение эффективности его практической организации обусловливают потребность в формировании специальной правовой базы. Федеральное законодательство, предметом которого является ГЧП, в России появилось только с 01.012016 г. (Федеральный закон от 13.072015 г. № 224-Ф3 «О государственночастном партнерстве, муниципально-частном партнерстве в Российской Федерации и внесении изменений в отдельные законодательные акты Российской Федерации» [7]).

Вместе с тем начиная с 2006 г. в России активно появляются первые региональные 
законы, посвященные ГЧП. Принятые в большинстве субъектов РФ законы об участии субъектов РФ в государственно-частных партнерствах должны быть приведены в соответствие с Федеральным законом № 224-ФЗ.

На данный момент для России проблема правового обеспечения ГЧП остается нерешенной.

Многое в становлении и развитии ГЧП определяется наличием соответствующей институциональной среды для решения стоящих перед государством задач, расстановкой социально-политических сил и преобладанием тех или иных политических доктрин. При этом речь идет не только о проявлении политической воли на высшем уровне, но и о создании «политического обеспечения» в нижних слоях общества путем подготовки общественного мнения к использованию приватизационных механизмов в сфере социальной и производственной инфраструктуры.

Основную роль в реализации стратегических планов по использованию ГЧП-проектов остаются играть факторы эффективности институциональной среды: обеспечение транспорентности работы бизнеса на объектах государственной и муниципальной собственности, выработка четких инструкций и рекомендаций, жесткая и последовательная реализация государством задекларированной политики, следование принципам ГЧП, стабильность политической системы.

Особую роль в странах с недостаточно совершенной институциональной средой рыночной экономики и гражданского общества играют внешние факторы, в том числе психологическое давление, связанное с успехами передовых стран, побуждающее иногда к копированию зарубежных моделей ГЧП без подготовки соответствующей институциональной, правовой и финансовой основы. Такая политика может привести к результатам, прямо противоположным тому, что ожидалось, и на долгие годы создать негативный имидж ГЧП.

Поэтому основными направлениями по совершенствованию и модернизации форм ГЧП в России должны стать:

- выработка стратегии социально-экономического развития с применением схем ГЧП в приоритетных отраслях;
- обеспечение жесткого соблюдения нормативно-правовой базы, определяющей сферу ГЧП;

- разработка схемы мониторинга ГЧПпроектов и действенной судебной защиты прав участников: государственных органов и частных отечественных и зарубежных инвесторов; внедрение мониторинга судебной практики по делам, связанным с реализацией ГЧП-проектов, и своевременное принятие мер по совершенствованию правовой базы в этой сфере гражданско-правовых отношений;

- обеспечение введения адекватной системы тарифов на использование объектов транспортной и иной инфраструктуры, созданной с помощью ГЧП-проектов;

- разработка проформ инвестиционных соглашений и создание четкого порядка их заключения с учетом полномочий государственных или муниципальных органов; создание механизма публичного предложения проектов инвесторам; решение вопросов бухгалтерского учета, амортизационной политики, налоговой нагрузки, учитывая, что при реализации сложных капиталоемких проектов с длительным периодом окупаемости налоговая нагрузка на инвесторов может быть значительной, что делает использование механизма ГЧП-проектов неэффективным;

- создание адекватной системы субсидирования и соответствующих инструментов для того, чтобы социально уязвимые слои населения не пострадали от реализации ГЧПпроектов;

- обеспечение контроля за экологичностью и природоохранными последствиями от реализации ГЧП-проектов.

Одной из перспективных мер может стать институциональное изменение государственного управления через переход на управление по результатам, что существенно повысит прозрачность и открытость принятия и исполнения государственных решений. Процесс внедрения управления по результатам имеет место в России, но проходит он нестабильно и фрагментарно. Информацию о ходе внедрения управления по результатам в России можно найти в докладе «Международный опыт разработки типовой модели описания государственных программ и проектов» Аналитического центра при Правительстве Рос- 
сийской Федерации [3]. В нем также делается обзор зарубежного опыта, в частности, применения при реализации государственных целевых программ механизма оценки их результата по программе PART [9].

Примером реализации подхода управления по результатам можно считать использование ГЧП-проектов, позитивно зарекомендовавших себя на Западе и в России, что демонстрирует опыт отдельных регионов. Однако отсутствие единого методического инструментария реализации ГЧП-проектов наряду с рассогласованностью федерального и регионального законодательства в этой сфере является серьезным препятствием на пути его развития. Одним из действенных направлений дальнейшего развития ГЧП в инновационной сфере России может стать кластерный подход. Но реализация такого сценария требует разработки продуманной концепции социально-экономического развития на долгосрочную перспективу на базе пролонгации «Концепции долгосрочного социально-экономического развития Российской Федерации на период до 2020 г.» при ее одновременной корректировке в соответствии с наработанным опытом реализации кластерной формы ГЧП в регионах.

Таким образом, основываясь на данных экспертных опросов и научных разработок проектов государственно-частного партнерства, можно предположить, что в вопросах повышения эффективности механизмов реализации «Общественного договора-2030» в России между государством, обществом и бизнесом предпочтение отдавалось повышению прозрачности деятельности органов государственной власти, а также доказавшему свою эффективность управлению по результатам.

\section{СПИСОК ЛИТЕРАТУРЫ}

1. Бальцерович, Л. Социализм, капитализм, трансформация: Очерки на рубеже эпох / Л. Бальцерович. - М. : Наука ; Изд-во УРАО, 1999. - 352 с.

2. Взаимодействие государства, бизнеса и гражданского общества : Информационно-аналитические материалы к проведению международного круглого стола. - Ростов н/Д : Изд-во СКАГС, 2012. $-184 \mathrm{c}$.
3. Доклад «Международный опыт разработки типовой модели описания государственных программ и проектов» / Федеральное государственное учреждение «Аналитический центр при Правительстве Российской Федерации» // Госбук : Экспертная сеть по вопросам государственного управления. - Электрон. текстовые дан. - Режим доступа: http://www.gosbook.ru/node/49685/ (дата обращения: 05.04.2016). - Загл. с экрана.

4. Игнатова, Т. В. Эффективность института государственно-частного партнерства как фактор инновационноориентированного развития России / Т. В. Игнатова, Т. П. Черкасова // Государственное и муниципальное управление : Ученые записки СКАГС. -2011. - № 1.- С. 103-112.

5. Распоряжение Правительства РФ от 17.11.2008 № 1662-р (ред. от 08.08.2009) «О Концепции долгосрочного социально-экономического развития Российской Федерации на период до 2020 года» (вместе с «Концепцией долгосрочного социально-экономического развития Российской Федерации на период до 2020 года»). - Электрон. текстовые дан. - Режим доступа: http:// www.consultant.ru/document/cons_doc_LAW 82134/ (дата обращения: 27.03.2016). - -Загл. с экрана.

6. Указ Президента РФ от 31 декабря 2015 г. № 683 «О Стратегии национальной безопасности Российской Федерации». - Электрон. текстовые дан. - Режим доступа: http://www.garant.ru/hotlaw/ federal/688504/\#ixzz3zAhdoxfp (дата обращения: 26.03.2016). - Загл. с экрана.

7. Федеральный закон от 13.07.2015 № 224-Ф3 (ред. от 29.12.2015) «О государственно-частном партнерстве, муниципально-частном партнерстве в Российской Федерации и внесении изменений в отдельные законодательные акты Российской Федерации». - Электрон. текстовые дан. - Режим доступа: http://www.consultant.ru/document/cons_doc LAW 182660/ (дата обращения: 27.03.2016). - Загл. с экрана.

8. Что такое «гражданское общество?» // Сайт ФОМ. - Электрон. дан. - Режим доступа: http://fom.ru/ TSennosti/12375 (дата обращения: 04.04.2016). - Загл. с экрана.

9. Instructions for the Program Assessment Ratings Tool. - Electronic text data. - Mode of access: http://207.245.165.145/omb/budintegration/ part_assessing2004.html (date of access: 05.04.2016). Title from screen.

\section{REFERENCES}

1. Baltserovich L. Sotsializm, kapitalizm, transformatsiya: Ocherki na rubezhe epokh [Socialism, Capitalism, Transformation: Essays at the 
Turn of the Eras]. Moscow, Nauka Publ.; Izd-vo URAO, 1999. $352 \mathrm{p}$.

2. Vzaimodeystvie gosudarstva, biznesa $i$ grazhdanskogo obshchestva: Informatsionnoanaliticheskie materialy $k$ provedeniyu mezhdunarodnogo kruglogo stola [The Interaction Between the State, Business and Civil Society. Information and Analytical Materials for an International Round Table]. Rostov-on-Don, Izd-vo SKAGS, 2012. $184 \mathrm{p}$.

3. Doklad "Mezhdunarodnyy opyt razrabotki tipovoy modeli opisaniya gosudarstvennykh programm i proektov". Federalnoe gosudarstvennoe uchrezhdenie "Analiticheskiy tsentr pri Pravitelstve Rossiyskoy Federatsii" [The Report "International Experience in the Development of Model Descriptions of State Programs and Projects". Federal State Institution "Analytical Center at the Government of the Russian Federation"]. Gosbuk: Ekspertnaya set po voprosam gosudarstvennogo upravleniya [State Book: Expert Network on Public Administration]. Available at: http://www.gosbook.ru/. (accessed April 5, 2016).

4. Ignatova T.V., Cherkasova T.P. Effektivnost instituta gosudarstvenno-chastnogo partnerstva kak faktor innovatsionno orientirovannogo razvitiya Rossii [The Effectiveness of the Institute of State-Private Partnership as a Factor of Innovation-Oriented Development of Russia]. Gosudarstvennoe $i$ munitsipalnoe upravlenie: Uchenye zapiski SKAGS, 2011, no. 1, pp. 103-112.

5. Rasporyazhenie Pravitelstva RF ot 17.11.2008 № 1662-r (red. ot 08.08.2009) «O Kontseptsii dolgosrochnogo sotsialno-ekonomicheskogo razvitiya Rossiyskoy Federatsii na period do 2020 goda» (vmeste $s$ "Kontseptsiey dolgosrochnogo sotsial'no-ekonomicheskogo razvitiya Rossiyskoy
Federatsii na period do 2020 goda») [The Decree of the Russian Government of November 17, 2008 no. 1662-r (amend. of August 8, 2009) "On the Concept of Long-Term Socio-Economic Development of the Russian Federation for the Period Till 2020" (Together With the "Concept of Long-Term Socio-Economic Development of the Russian Federation for the Period Till 2020”)]. Available at: http://www.consultant.ru/ document/cons doc LAW 82134/. (accessed March 27, 2016).

6. Ukaz Prezidenta RF ot 31 dekabrya $2015 \mathrm{~g}$. № 683 "O Strategii natsionalnoy bezopasnosti Rossiyskoy Federatsii" [The Decree of the President of the Russian Federation of December 31, 2015 no. 683 "On the Strategy of National Security of the Russian Federation"]. Available at: http://www.garant.ru/ hotlaw/federal/688504/\#ixzz3zAhdoxfp. (accessed March 26, 2016).

7. Federalnyy zakon ot 13.07.2015 № 224-FZ (red. ot 29.12.2015) "O gosudarstvenno-chastnom partnerstve, munitsipalno-chastnom partnerstve $v$ Rossiyskoy Federatsii i vnesenii izmeneniy v otdelnye zakonodatelnye akty Rossiyskoy Federatsii" [The Federal Law of July 13, 2015 no. 224-FL (amend. of December 29, 2015) "On Public-Private Partnership, Municipal-Private Partnership in the Russian Federation and Introducing Amendments to Certain Legislative Acts of the Russian Federation]. Available at: http://www.consultant.ru/document/cons_doc_ LAW_182660/. (accessed March 27, 2016).

8. Chto takoe "grazhdanskoe obshchestvo?" [What Is "Civil Society?"]. FOM Website. Available at: http://fom.ru/TSennosti/12375. (accessed April 4, 2016).

9. Instructions for the Program Assessment Ratings Tool. Available at: http://207.245.165.145/omb/ budintegration/part_assessing2004.html. (accessed April 5, 2016).

\section{Information About the Authors}

Aleksandr V. Ponedelkov, Doctor of Sciences (Politics), Professor, Head of Department of Political Science and Ethnic Policy, South-Russian Institute of Management - Branch of Russian Presidential Academy of National Economy and Public Administration, Pushkinskaya St., 70, 344002 Rostov-on-Don, Russian Federation, ponedelkov@uriu.ranepa.ru.

Svetlana I. Kuzina, Doctor of Sciences (Politics), Professor, Department of Political Science and Ethnic Policy, South-Russian Institute of Management - Branch of Russian Presidential Academy of National Economy and Public Administration, Pushkinskaya St., 70, 344002 Rostov-on-Don, Russian Federation, svivk@yandex.ru.

Tatyana P. Cherkasova, Doctor of Sciences (Economics), Associate Professor, Dean of the Faculty of Political Science, South-Russian Institute of Management - Branch of Russian Presidential Academy of National Economy and Public Administration, Pushkinskaya St., 70, 344002 Rostov-on-Don, Russian Federation, publicadm@mail.ru. 


\section{Информация об авторах}

Александр Васильевич Понеделков, доктор политических наук, профессор, заведующий кафедрой политологии и этнополитики, Южно-Российский институт управления - филиал РАНХиГС при Президенте РФ, ул. Пушкинская, 70, 344002 г. Ростов-на-Дону, Российская Федерация, ponedelkov@uriu.ranepa.ru.

Светлана Ивановна Кузина, доктор политических наук, профессор кафедры политологии и этнополитики, Южно-Российский институт управления - филиал РАНХиГС при Президенте РФ, ул. Пушкинская, 70, 344002 г. Ростов-на-Дону, Российская Федерация, svivk@yandex.ru.

Татьяна Павловна Черкасова, доктор экономических наук, доцент, декан факультета политологии, Южно-Российский институт управления - филиал РАНХиГС при Президенте РФ, ул. Пушкинская, 70, 344002 г. Ростов-на-Дону, Российская Федерация, publicadm@mail.ru. 